\title{
Intracellular levels of calmodulin are increased in transformed cells
}

WANG Ruihong, Hongqing ZHANG, Suwen LI and Shaobai XUE

Department of Biology, Beijing Normal University, Beijing 100875, China

\begin{abstract}
By using Hoechst 33342, rabbit anti calmodulin antibody,FITC-labeled goat anti rabbit IgG and SR101(sulfo rhodamine 101)simultaneously to stain individual normal and transformed cells, the microspectrophotometric analysis demonstrated that 3 markers which represented the nucleus, calmodulin and total protein respectively, could be recognized in individualj cells without interference. The phase of the cell cycle was determined by DNA content (Hoechst 33342). We found that in transformed cells (NIH3T3) tsRSV-LA90,cultured at $33^{\circ} \mathrm{C}$ and transformed C3H10T1/ 2 cells), the ratio of calmodulin to total protein (based on the phases of cell cycle)was higher than that in normal cells (NIH3T3 tsRSV-LA90 cells, cultured at $39^{\circ} \mathrm{C}$ and C3H10T1/2 cells)in every cell cycle phase. This ratio increased obviously only from $\mathrm{G}_{1}$ to $\mathrm{S}$ phase in either normal or transformed cells. The results showed that calmodulin really increased during the transformation, and its increase was specific. In the meantime when cells proceeded from $\mathrm{G}_{1}$ to $\mathrm{S}$, the intracellular calmodulin content also increased specifically.
\end{abstract}

Key words: calmodulin, microspectrophotometry, trans for mation, cell cycle.

\section{INTRODUCTION}

Calmodulin $(\mathrm{CaM})$ is the major intracellular $\mathrm{Ca}^{2+}$ binding protein, participating in many elementary metabolisms in the cell, so its role in the regulation of cell transformation and proliferation should by no means be overlooked [1]. Many authors have suggested that the activity of CaM would be primarily regulated by alteration in the net flux 
Calmodulin level is increased in transformed cell

or distribution of $\mathrm{Ca}^{2+}$ and not by change in the intracellular concentration of this protein[2]. However, an increase in the amount of CaM relative to total protein has been reported in chicken embryo fibroblasts transformed by Rous sarcoma virus, with CaM level quantified by either densitometric scanning of polyacrylamide gels [3] or bioassay [4], but it has not been verified if this increase was true in individual cells. In 1981,by the means of radioimmunoassay, it was reported that the transformation by oncogenic viruses resulted in an increase in the number of CaM molecules per cell by preferentially stimulating the synthesis of this protein, whereas no such elevation was observed in case of tubulin; and the increase of CaM in transformed cells amounted to 2 folds [5].

Neither results were based on individual cell study, We have demonstrated that intracellular CaM level was increased from G1 through S to $\mathrm{G}_{2} \mathrm{M}[6]$, Although there was a report that total protein was increased along the cell cycle too[7],it is unclear whether the increase of intracellular level of CaM represented a true increase in the total intracellular level of this protein. The present work was undertaken in order to determine whether the rise of specific activity actually represents an increase of CaM molecules per cell based on the ratio of CaM to protein in individual cells and whether such change denotes a more general response to transformation by oncogenic viruses and irradiation as well.

Two cell systems were chosen for these studies:one is temperature sensitive (ts) mutant of NIH3T3 cells transformed by a tsRSV,the other is C3H10T1/2 cells and their counterparts transformed by irradiation. Because the intracellular level of CaM is a function of the total protein, we have developed a procedure to measure DNA,CaM and protein in individual cells and to get the ratio of CaM to total protein and to ascertain the phase of cell cycle in individual cells.

We also demonstrated that transformation by oncogenic viruses and irradiation resulted in a real increase in the intracellular level of CaM per cell based on their phases in the cell cycle.

\section{MATERIALS AND METHODS}

\section{Cell cultures}

NIH3T3 cells and NIH3T3 tsRSV-LA90 cells were given by Prof. Ian, G. Macara (Rochester University, New York,USA) as a gift.

NIH3T3 tsRSV-LA90 cells were obtained from temperature sensitive mutant of Rous sarcoma virus transforming mouse NIH3T3 cells. When cultured at nonpermissive temperature $39-40^{\circ} \mathrm{C}, v$-src gene was shut off, and its product pp $60^{\nu-s r c}$ became inactive, and the cells remained phenotypically normal. When grown at permissive temperature $33^{\circ} \mathrm{C}, v$-src gene was expressed, and its product was active having tyrosine -kinase activity, so the cells were in transformed state.

NIH3T3 cells and NIH3T3 tsRSV-LA90 cells were maintained at $37^{\circ} \mathrm{C}$ in humidified atmosphere of $5 \% \mathrm{CO}_{2}$ in Dulbecco's modified Eagle's medium(DMEM),supplemented with $10 \%$ calf serum. The cells were moved to $33^{\circ} \mathrm{C}$ or $39^{\circ} \mathrm{C}$ when the experiments were being done.

C3H10T1/2 and transformed C3H10T1/2 (TC3H10T1/2) cells were given by Profs. Changqing Pu and Shuqing Ge (The Industry Hygiene Institute, Beijing,China). The TC3H10T1/2 cells were obtained by tritium irradiation.

$\mathrm{C} 3 \mathrm{H} 10 \mathrm{~T} 1 / 2$ and TC3H10T1/2 cells were cultured at $37^{\circ} \mathrm{C}$ in humidified atmosphere of $5 \% \mathrm{CO}_{2}$ in DMEM,supplemented with $15 \%$ calf serum.

While the experiments were being carried out, the cells were grown on coverslips and kept at a density of $60 \%$. At this density, the cells would not become confluent. 
Wang $\mathrm{RH}$ et al.

\author{
Simultaneous fluorescent staining and quantitative analysis for DNA, CaM and total pro- \\ tein.
}

DNA was stained with Hoechst 33342(Ho33342 Sigma). Intracellular CaM was detected by indirect immunofluorescent staining with anti CaM antibodies and SR101 was used to stain intracellular total proteins. Cells were cultured on coverslips when the density reached $60 \%-70 \%$, and then picked out. At first, the coverslips Were washed by PBS, fixed with methanol: acetone $(1: 1)$ at $20^{\circ} \mathrm{C}$ for $5 \mathrm{~min}$. Secondly, the cells were incubated with rabbit anti CaM antibodies (purchased from Biochemistry Lab, Xuzhou Medical College and its specificity has been checked)at $37^{\circ} \mathrm{C}$ for $1 \mathrm{~h}$. Then washed with PBS 3 times. Thirdly, the cells were restained with FITC IgG of goat anti rabbit IgG (purchased from Beijing Biological Product Institute) at $37^{\circ} \mathrm{C}$ for $1 \mathrm{hr}$ and washed with PBS 3 times. Fourthly the cells were covered with $3 \mu \mathrm{g} / \mathrm{ml}$ SR101 for $30 \mathrm{~min}$ at room temperature avoiding light [8], washed with PBS 3 times and at last stained with $10 \mu M$ Ho33342 for 30min at room temperature in the dark. And finally, the coverslips were washed with PBS 3 times and DDW(double distilled water) once, sealed with glycerine: PBS(9:1 ,pH 8.0)and nail polish.

\title{
Spectral analysis and quantitative analysis of DNA, CaM and total protein in individual cells
}

The fluorescence emission spectra of individual cells stained with Ho33342, anti CaM antibody, FITC labeled goat antirabbit IgG antibody and SR101 respectively were obtained with a Leitz MPV II microspectraphotometer and recorded on a X Y recorder. The fluorescence intensity of Ho33342, FITC and SR101 in individual cells was measured with the same microspectrophotometer. It was equipped with a Ploempark epiilluminater and 100W Hg lamp. The Ho33342 fluorescence was measured with an A2 filter block consisting of a bandpass filter (270-380 nm), a RKP 380 dichroic mirror and a BP410 $-580 \mathrm{~nm}$ bandpass barrier filter. The FITC fluorescence was measured with a I2 filter block consisting of blue excitation filter (450-490 nm bandpass filter), RKP510 $\mathrm{nm}$ dichroic mirror and a built in LP515 barrier filter. The SR101 fluorescence was measured with a N2.1 filter block consisting of green excitation filter (515-560 nm bandpass filter), RKP580 dichroic mirror and a built in high pass 580 barrier filter. The data were presented as bivariate dot plot or histogram.

\section{RESULTS}

\section{Fluorescence analysis and spectral resolution of the 3 dyes}

In Fig 1, it can be seen that maximum emissions of Ho33342, FITC and SR101 were obtained by excitation with UV,blue and green light respectively. The emissions of Ho33342, FITC and SR101 excited at wavelengths other than the maximum excitation region were very weak. According to the above stated results, it may be said that the 3 types of flunorescence could be clearly distinguished without interference from each other under the conditions just discribed. Thus one could obtain the correlated measurements of DNA, CaM and protein in the individual cells.

\section{CaM content during the cell cycle of NIH3T3 cells}

Fig 2 and Table 1 illustrated the 2 parameter dot plot for DNA vs CaM level of NIH3T3 cells cultured at 33,37 and $39^{\circ} \mathrm{C}$. Analysis of the CaM in relation to the phase of cell cycle based on DNA content revealed a characteristic pattern of the change of $\mathrm{CaM}$ content, indicating a gradual increase of CaM from $\mathrm{G} 1$ to $\mathrm{G}_{2} \mathrm{M}$, which was quite evident from $\mathrm{G}_{1}$ to $\mathrm{S}$ phase.

Comparing the $\mathrm{CaM}$ content among the cells at 33,37 and $39^{\circ} \mathrm{C}$ in the same cell cycle 


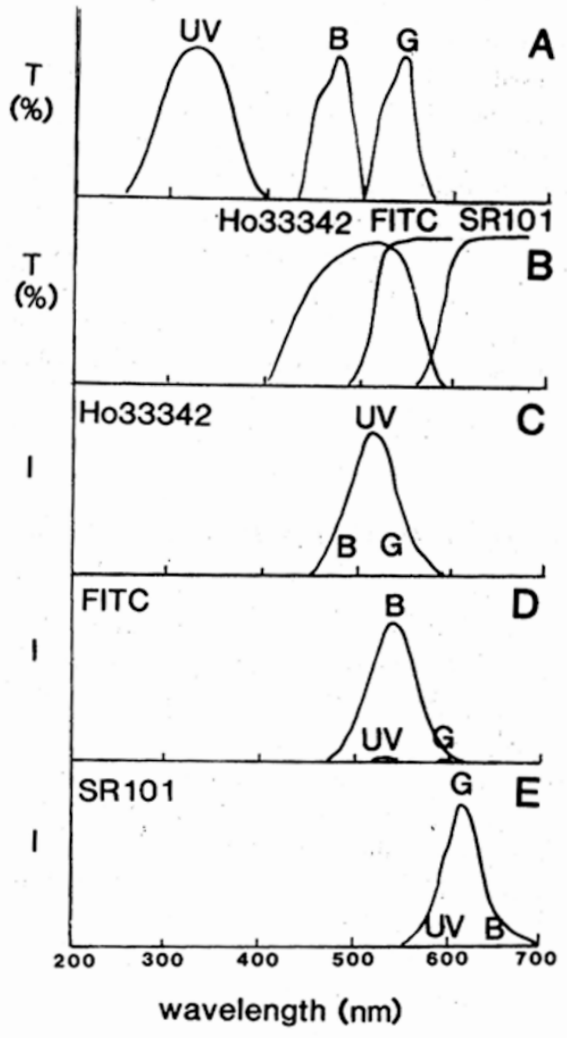

Fig 1. Fluorescence spectra resolution. A: Spectral characteristics for excitation. B: Spectral characteristics for fluorescence measurement for Ho33342, FITC and SR101 respectively. C, D, and E:Fluorescence mission spectra for cells stained with only one dye and excited with UV,blue(B) and green (G) light respectively. T, transparency. I, relative fluorescence intensity.

Tab 1. The mean value of calmodulin in NIH3T3 cells.

\begin{tabular}{c|c|c|c|c}
\hline \multirow{2}{*}{ Cell } & Temp & \multicolumn{2}{|c}{ Mean value of calmodulin in different phase } \\
\cline { 2 - 5 } & ${ }^{\circ} \mathrm{C}$ & $\mathrm{G} 1$ & $\mathrm{~S}$ & $\mathrm{G}_{2} \mathrm{M}$ \\
\hline NIH3T3 & 37 & $20.49 \pm 8.40$ & $34.77 \pm 12.22$ & $26.82 \pm 13.97$ \\
\hline NIH3T3 & 33 & $26.45 \pm 8.57$ & $39.33 \pm 7.20$ & $40.38 \pm 11.4$ \\
\hline NIH3T3 & 39 & $20.62 \pm 6.89$ & $25.83 \pm 6.95$ & $44.20 \pm 10.08$ \\
\hline & & $\begin{array}{l}\mathrm{P}_{1}>0.1 \\
\mathrm{P}_{2}>0.1 \\
\mathrm{P}_{3}>0.1\end{array}$ & $\begin{array}{l}\mathrm{P}_{1}>0.1 \\
\mathrm{P}_{2}>0.1 \\
\mathrm{P}_{3}>0.1\end{array}$ \\
\hline
\end{tabular}

P1,P2 represcented t test between CaM content of NIH3T3 cells cultured at $33^{\circ} \mathrm{C}$ or $39^{\circ} \mathrm{C}$ paired with those cells cultured at $37^{\circ} \mathrm{C}$ respectively. P3 represented t test of NIH3T3 cells cultured at $33{ }^{\circ} \mathrm{C}$ paired with these cultured at $39^{\circ} \mathrm{C}$.

phase, there were no notable statistical differences. So the change of temperature did not induce the alteration of intracellular calmodulin level in NIH3T3 cells. 
Wang RH et al.
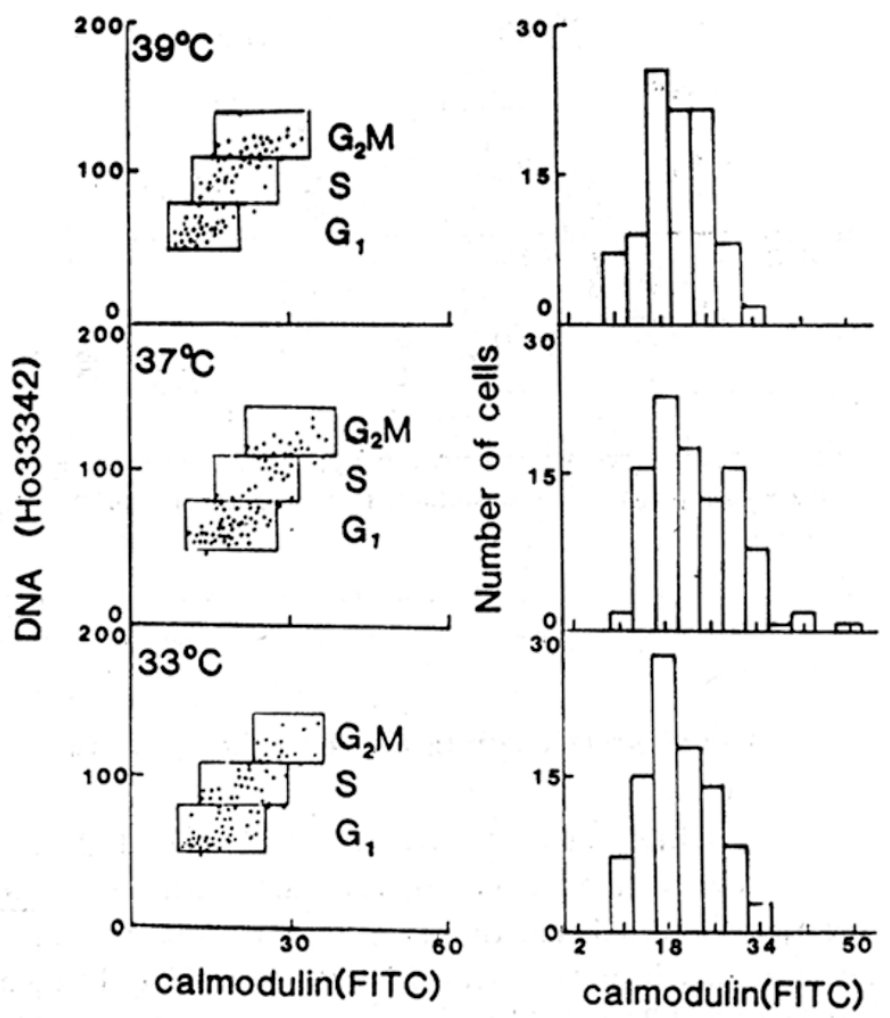

Fig 2. Two - parameter dot plot for DNA vs calmodulin and histogram of calmodulin content of NIH3T3 cells cultured at $39^{\circ} \mathrm{C}, 37^{\circ} \mathrm{C}$ and $33^{\circ} \mathrm{C}$.

CaM, protein, the ratio of CaM to total protein during the cell cycle of NIH $3 \mathrm{~T} 3$ tsRSV - LA9O cells

Fig 3 and Tab 2 showed the results of NIH3T3 tsRSV-LA90 cells stained with these 3 dyes simultaneously. It could be seen that intracellular CaM level was elevated and total protein content was augumented accompanied with a DNA content increase both at $33^{\circ} \mathrm{C}$ and $39^{\circ} \mathrm{C}$. On the other hand, the most important thing was in each phase of cell cycle in NIH3T3 tsRSV-LA90 cells, the intracellular ratio of CaM to total protein raised to 2 fold higher at $33^{\circ} \mathrm{C}$ than that at $39^{\circ} \mathrm{C}$ in the corresponding phase.

Tab 2. The mean value of the ratio of calmodulin to total protein in NIH3T3 tsRSV-LA90 cells.

\begin{tabular}{c|c|c|c|c}
\hline \multirow{2}{*}{ Cell } & \multicolumn{3}{|c|}{ The mean value of the ratio in } \\
different phases & \multirow{2}{*}{} \\
\cline { 2 - 5 } & $\mathrm{G}_{1}$ & $\mathrm{~S}$ & $\mathrm{G}_{2} \mathrm{M}$ & \\
\hline $33^{\circ} \mathrm{C}$ LA -90 & $13.55 \pm 2.23$ & $16.28 \pm 2.40$ & $17.17 \pm 3.04$ & $\mathrm{P}_{1}<0.001, \mathrm{P}_{2}>0.1$ \\
\hline $39^{\circ} \mathrm{C}$ LA -90 & $4.98 \pm 2.07$ & $8.29 \pm 3.29$ & $9.55 \pm 0.82$ & $\mathrm{P}_{1}<0.001, \mathrm{P}_{2}>0.1$ \\
\hline $\mathrm{t}$ test & $\mathrm{P}<0.0001$ & $\mathrm{P}<0.0001$ & $\mathrm{P}<0.0001$ & \\
\hline
\end{tabular}

$\mathrm{P}$ is the result of $\mathrm{t}$ test comparing the ratio of the same phase in different state of NIH3T3 tsRSV-LA90 cells $\mathrm{P}_{1}, \mathrm{P}_{2}$ represent the result of $t$ test of $\mathrm{G}_{1}$ pairing with $\mathrm{S}$ or $\mathrm{S}$ pairing with $\mathrm{G}_{2 \mathrm{M}}$ in the same cells respectively. 
Calmodulin level is increased in transformed cell

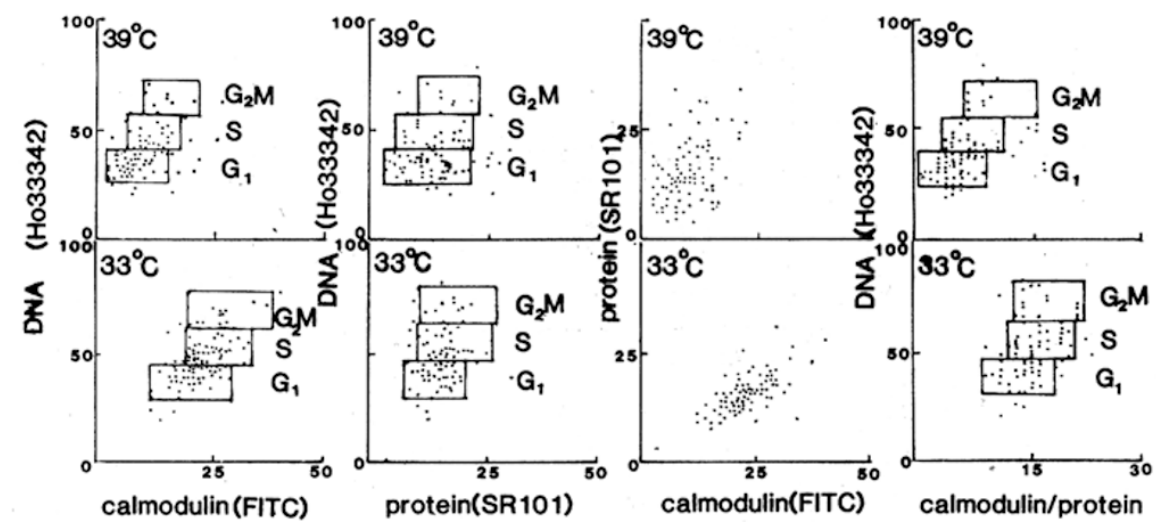

Fig 3. Two - parameter dot plot for DNA vs calmodulin. DNA vs ptotein calmodulin vs protein, and DNA vs the ratio between calmodulin to protein of NIH3T3 tsRSV-LA90 cells cultured at $33^{\circ} \mathrm{C}$ and $39^{\circ} \mathrm{C}$.

The ratio of CaM to total protein during the cell cycle of C3H1OT1/2 and TC3H1OT1/2 cells

Fig 4 and Tab 3 illustrated the results of C3H10T1/2 and TC3H10T1/2 cells stained simutaneously with SR101, Ho33342 and anti-CaM indirect immunofluorescence, which demonstrated that the ratio of CaM to protein in transformed cells was 3 times higher than that in normal C3HT101/2 cells. The differences in DNA content between C3H10T1/2 and TC3H10T1/2 cells was due to the loss of chromosomes by tritium irradiation.

Tab 3. The mean value of the ratio of calmodulin to total protein in normal and transformed C3H10T1/2 cells.

\begin{tabular}{c|c|c|c|c}
\hline \multirow{2}{*}{ Cell } & \multicolumn{3}{|c|}{$\begin{array}{c}\text { Mean of CaM/total protein in } \\
\text { different phases }\end{array}$} & \\
\cline { 2 - 5 } & $\mathrm{G}_{1}$ & $\mathrm{~S}$ & $\mathrm{G}_{2} \mathrm{M}$ & \\
\hline C3H10T1/2 & $8.89 \pm 3.25$ & $10.31 \pm 2.19$ & $31.00 \pm 0.82$ & $\mathrm{P}_{1}<0.001, \mathrm{P}_{2}>0.1$ \\
\hline TC3H10T1/2 & $26.00 \pm 4.62$ & $32.7 \pm 7.00$ & $\mathrm{P}_{1}<0.001, \mathrm{P}_{2}>0.1$ \\
\hline t test & $\mathrm{P}<0.001$ & $\mathrm{P}<0.001$ & $\mathrm{P}<0.001$ & \\
\hline
\end{tabular}

$\mathrm{P}$ is the $\mathrm{t}$ test value of $\mathrm{C} 3 \mathrm{H} 10 \mathrm{~T} 1 / 2$ pairin with TC3H10T1/2 cells in the same cell cycle phase. $\mathrm{P} 1$ and $\mathrm{P} 2$ represent the $t$ test of G1 pairing with S or S pairing with G2M in the same cells respectively.

Thus, the CaM level increase in transformed cells was a real one. The difference of CaM level between normal and transformed cells was not the result of intracellular protein increase, but a general phenomenon of CaM elevation in cell transformation induced either by virus or radiation.

\section{Change of calmodulin content during cell cycle}

Taken together the results obtained with NIH3T3 tsRSV -LA90 cells, C3H10T1/2 cells and their transformed counterparts stained with SR101,FITC,Ho33342 and compared with the ratio of different phases of cell cycle in either normal or transformed cells 


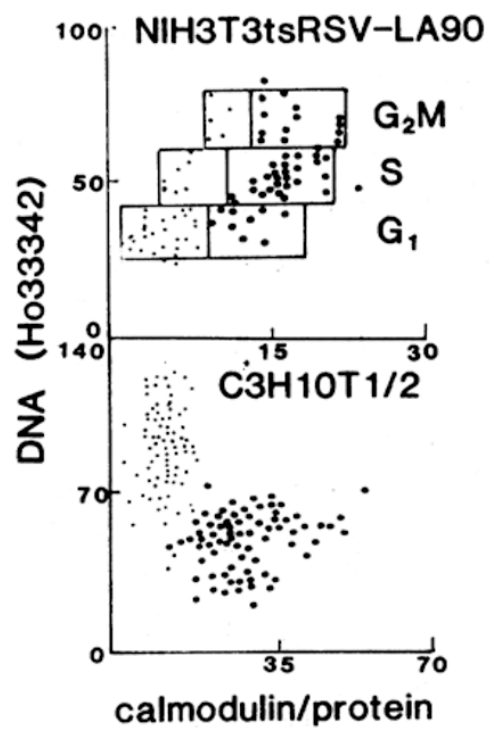

Fig 4. Overlay of two - parameter dot plot for DNA vs the ratio between calmodulin to protein of NIH3T3 tsRSV-LA90 cells cultured at $33^{\circ} \mathrm{C}(\bullet)$ and $39^{\circ} \mathrm{C}(\bullet)$, and $\mathrm{C} 3 \mathrm{H} 10 \mathrm{~T} 1 / 2(\bullet)$ and TC3H10T1/2 cells

by t test, we found that during cell cycle the CaM increase was obvious and specific only from $\mathrm{G}_{1}$ phase to $\mathrm{S}$ phase.

\section{DISCUSSION}

In this study, we have developed a procedure to quantify simultaneously DNA, $\mathrm{CaM}$ and total protein in individual cells. The advantage of multivariate correlated determination is that we could get the ratio of CaM to protein vs DNA content in individual cells and compare the true CaM changes between the normal and transformed cells based on their phases in the cell cycle.

From the experimental system we used, especially the temperature sensitive mutant, it is clear that the role of CaM in cellular transformation would be best studied in cells that can be rapidly and reversibly switched from the neoplastic to non - neoplastic state.

Since we got the ratio of CaM to total protein which represented the change of intracellular CaM corresponding to the change of intracellular total protein, we verified that there was a specific and true elevation of the level of CaM in transformed phenotype. The results presented here were the same as those previously reported[3, 9-12]. But the methods which had previously been used were mostly cyclic nucleotide phosphodiesterase (PDE) method and radioimmunoassay. These methods are good for measuring the CaM activity and quantifying the CaM level. However, there are marked differences in the level of intracellular $\mathrm{CaM}$ in $\mathrm{G}_{1}, \mathrm{~S}$ or $\mathrm{G}_{2} \mathrm{M}$ cell cycle phases. The amount of intracellular CaM in $\mathrm{G}_{2} \mathrm{M}$ phase is almost 2 times higher than that of the cells in $\mathrm{G}_{1}$ phase[6. 13]. It would be better to compare the cells in the same phase in studying the change of $\mathrm{CaM}$ content between transformed and nontransformed phenotypes.

Moreover, because the content of intracellular total protein increased as the cell cycle was proceeding [7], it remained yet unsettled whether the raise in the levels of CaM 
in transformed cells was only responsible to the increment of total intracellular protein, but not specific to transformation. Although Chafouleas et al had clarified the true increase of CaM referring to the change of tubulin [5], an increase of the tubulin level during cell cycle has also been reported[14].

In this paper, we reported that total intracellular levels of CaM were increased truly and specifically in mammalian tissue culture cells transformed by RNA virus (tsRSV) and irradiation. By considering, the conclusions reached by other authors from studying the cells transformed by DNA virus[5] or chemical substances and tumor cells[12], we could affirm that the increase of intracellular CaM is a general event after cell transformation.

$\mathrm{CaM}$ is a multifunctional protein. It modulates a lot of intracellular essential physiological processes, such as cyclic nucleotide and glycogen metabolism, calcium dependent protein phosphorylation, cell division and other cellular motilities[2]. The overall function of this protein is to balance all the systems involving in the regulation of cellular activities. The increase of the intracellular level of CaM may derange this balance and lead to the changes of cell morphology, cyclicnucleotide metabolism, metabolic and intracellular calcium level and so on. In the end, all these changes may result, in the case of in vitro transformed cells, in the loss of anchorage dependence and in the decrease of their requirement to extracellular calcium concentration.

The mechanism of the elevation of intracellular level of CaM during cellular transformation remained elusive. The main viewpoints which had been raised include: (a) Change of cytoskeleton - CaM regulated the assembly and disassembly of microtubule directly, suggesting that the direct target of the CaM augumentation might be the microtubule net work,leading to its rearrangment and abnormal proliferation[5]. (b)Loss of confQDluent inhibition - lack of down -regulation of CaM level in transformed cells made it possible that PDE could maintain in high activity, and the amount of cAMP could be very low even when the cells became confluent[3.10]. (c) Change of the response to cAMP and cGMP - $\mathrm{Ca}^{2+}-\mathrm{CaM}$ may directly contribute to an overall decrease in the tumor cells ability to respond to cAMP and an overall increase in ability to respond to cGMP[9]. (d) Nothing to do with cell transformation - the reduced calcium dependence of transformed phenotype was not likely due to a diminished requirement for $\mathrm{Ca}^{2+}-\mathrm{CaM}$ in later $\mathrm{G}_{1}$ phase or to an increase in intracellular CaM levels [11]. (e) DNA Synthesis-CaM took part in modulating cell proliferation, and this acted mainly on DNA synthesis[12]. The observation showed that at $\mathrm{G}_{1} / \mathrm{S}$ transition, CaM could combine with DNA polymerase a, suggesting the regulation of the activity of DNA polymerase a in vivo by CaM. Alternatively, CaM might play a role in the process controlling the inactivation/reactivation cycle of replicons which took place at each cycle of DNA synthesis[15]. According to our own observations we thought, ,(a), (c) and (e) may be more probable in explaining the mechanism how the elevation of CaM promotes the cell transformation.

Furthermore, the level of the product pp34 $4^{\mathrm{cdc} 2}$ of cdc2 gene which regulated cell transformation did not vary through the cell cycle, but the phosphorylation of pp34 ${ }^{\text {cdc2 }}$ (on serine residue) was required for $\mathrm{G}_{1} / \mathrm{S}$ transition in fission yeast and mammalian cells [16]. $\mathrm{Ca}^{2+}-\mathrm{CaM}$ could activate many kinds of serine -kinases. This might be related to 
the mechanism by which CaM was increased obviously during $\mathrm{G}_{1} / \mathrm{S}$ transition, and it might also be the main reason for the transformed cells to proliferate indefinitely.

However, cell transformation is a rather complicated biological process and the underlying mechanism of the increase of intracellular CaM level during this process and its relation to the regulation of cell proliferation and transformation await further investigation.

\section{ACKNOWLEDGEMENT} China.

project supported by the National Natural Science Foundation and SECFD of

\section{REFERENCES}

[1] Wen YY et al: Calcium - calmodudin and caveinoma. In:Calcium and Calmodulin. published by Chemical Industry Publishing House of Beijing,in Chinese : 1989; P218

[ 2 ] Means AR \& Dedman JR. Calmodulin - an intracellular calcium receptor. Nature, 1980 ; 285: 73 - 7.

[ 3 ] Watterson DM, Ven Eldik L J, Smith RE \& Vanaman TC. Calmodulin - dependent regulatory protein of cyclic nucleotide metabolism in normal and transformed chicken embryo fibroblasts. Proc. Natl. Acad. Sci. USA. 1976;73:2711 - 15 .

[4] LaPort DC, Cidwitz S, Weber MJ \& Storm DR. Relationship between changes in the calcium dependent regulatory protein and adenylate cyclase during viral transformation. Biochem. Biophys. Res. Commun. 1979; 86: 1169 - 77.

[5 ] Chafouleas G J, Pardue RL, Brinkley BR,Dedman JR and Means AR. Regulation of intracellulur levels of calmodulin and tubulin in normal and transformed cells. Proc. Natl. Acad. Sci. USA. 1981; 78: 996-1000.

[ 6 ] You JS, Li SW, Wang DS, Zhang Y, Suen DY and Xue SB. The distribution of calmodulin and $\mathrm{Ca}^{2+}$-activated calmodulin in cell cycle of mouse erythroleukemia cells. Cell Research. 1990; 1:89 - 94

[ 7 ] Crissman HA, Darzynkiewicz Z, Tobey RA and Steinkamp IA. Normal and Perturbed Chinese Hamster ovary cells: Correlation of DNA, RNA, and protein content by flow cytometry. The Journal of Cell Biology. 1985; 101:141 -7

[ 8 ] Engelbard III HH, Likrupka J and Backer KD. Simultaneous quantification of c -myc oncoprotein, total cellular protein, and DNA content using multiparamenter flow cytometry. Cytometry. 1991; $12: 68$ - 76.

[ 9 ] Criss WE and Kakiuchi S. Calcium: calmodulin and cancer. Feder Proc. 1982 ; 41,No. 7:2289 - 91.

[10] Viegl ML, Vanaman TC, Branch ME and Sedwick WD. Differences in calmodulin levels of normal and transformed cells as determined by culture conditions. Cancer Res. 1984; 44:3184 - 9.

[11] Durkin JP, Whitefield JF and MacManus JP. The role of calmodulin in the proliferation of transformed and phenotypically normal tsRSV- infected rat cells. J. Cell. Phys. 1983; 115:313 - 9.

[12] MacManus JP,Btaceland BM, Rixon RH, Whitefield JF and Morris HP. An increase in calmodulin during growth of normal and cancerous liver in vivo. FEBS LETTERS. 1981; 133:99 - 102.

[13] Chafouleas JG, Bolton WE, Hidaks H, Boyd III AE and Means AR. Calmodulin and the cell cycle: Involvement in regulation of cell - cycle progression. Cell. 1982; 28:41 - 50.

[14] Wang DS, Li SW, Zheng CQ, Cheng RX and Xue SB. Microtubule and microfilament distribution and tubulin content in the cell cycle of Indian muntjac cells. Cytometry. 1988; 9:368 -73.

[15] Rasmussen CD and Means AR. Calmodulin, cell growth and gene expression. Trends in Neuroscience. 1989; 12. No. 11: 433-8.

[16] Banjamin Lewin. Driving the cell cycle: M phase kinase, its partners and substrates. Cell. 1990; 61:743 -52.

Received 7 - 8 - 1991. Revised 14 - 11 - 1991. Accepted 4 - 12 - 1992. 